Genetic Epidemiology 16:40-53 (1999)

\title{
Genetic and Environmental Contributions to Size, Color, Shape, and Other Characteristics of Melanocytic Naevi in a Sample of Adolescent Twins
}

\author{
Bruce McGregor, John Pfitzner, Gu Zhu, Marlene Grace, Ann Eldridge, \\ John Pearson, Carol Mayne, Joanne F. Aitken, Adele C. Green, and \\ Nicholas G. Martin*
}

\section{Queensland Institute of Medical Research, Brisbane, Australia}

\begin{abstract}
The presence of melanocytic naevi is the strongest known risk factor for malignant melanoma. We have developed a computer imaging system with which it is possible to make quantitative measures of the size, color, and shape of pigmented lesions. The objective of this study was to examine the genetic and environmental contributions to these characteristics of naevi as measured by computer image analysis in a sample of adolescent twins. We captured video images of the 5 most atypical pigmented skin lesions (i.e., the largest, darkest, or most irregularly shaped) on each individual from 322 Australian adolescent twin pairs. Features extracted by computer image analysis for each lesion included color, size, symmetry, elongation, boundary irregularity, and edge distinctness. We found major genetic influences on the color and size of lesions accounting for between 40 and $80 \%$ of total variance. There were significant components of shared environmental influence $(22-45 \%$ of total variance) for the color variables, with sun exposure the most obvious explanation. Differences between individuals in naevus color and size are largely genetic in origin although there are significant environmental contributions to color as well. Genet. Epidemiol. 16:40-53, 1999. () 1999 Wiley-Liss, Inc.
\end{abstract}

Key words: moles; melanocytic naevi; melanoma; image analysis; twins; genetics

*Correspondence to: Dr. N.G. Martin, Queensland Institute of Medical Research, PO Royal Brisbane Hospital, Brisbane 4029, Australia. E-mail: nickM@qimr.edu.au

Received 13 August 1997; Revised 17 December 1997; Accepted 21 December 1997.

(C) 1999 Wiley-Liss, Inc. 


\section{INTRODUCTION}

During the past two decades, the incidence of malignant melanoma has more than doubled in white-skinned populations throughout the world [MacLennan et al., 1992]. The presence of melanocytic naevi is the strongest known risk factor for this disease [Swerdlow and Green, 1987], in particular the presence of naevi that are larger than $5 \mathrm{~mm}$ in diameter, have variable color, and an irregular edge [Swerdlow et al., 1986]. As the incidence of melanocytic naevi peaks around the age of puberty [Green and Swerdlow, 1989], knowledge of naevus development in adolescents may further our understanding of the causes of malignant melanoma.

Ecological studies point to exposure to solar ultraviolet radiation as a major environmental risk factor for naevi [Kelly et al., 1994], although the large variation in individual naevus counts within populations receiving uniformly high sun exposure [Aitken et al., 1994] suggests that other factors are involved. Strong familial correlations for total naevus number and naevus density have been demonstrated [Goldgar et al., 1991; Duffy et al., 1992; Briollais et al., 1996]. However, there is currently no clear evidence for the role of genetic factors in naevus development, and in particular for those characteristics of naevi that most clearly define melanoma risk, namely naevus size, color, and shape.

We have developed a computer imaging system for characterizing pigmented lesions [Green et al., 1991, 1994]. In a digital image of the skin surface, lesions can be isolated by their color and brightness from surrounding skin [Aitken et al., 1996] and it is thus possible to make quantitative measures of the color, size, and shape of pigmented lesions. We have shown that the area, perimeter, regularity of outline, color variation, and distinctness of boundary of lesions can be measured with moderate to high reliability using this imaging system [Aitken et al., 1996]. The main aim of this study was to examine the genetic and environmental contributions to the size, color, shape, and other characteristics of melanocytic naevi as measured by computer image analysis in a sample of adolescent twins.

\section{METHODS}

\section{Subjects and Clinical Examinations}

Subjects were enlisted by contacting the principals of the primary schools in the Brisbane Statistical Division, seeking twins aged from 10 to 12 years to take part in a longitudinal study of the development of melanocytic naevi (moles). Subjects were also ascertained by word of mouth, and media appeals. Informed consent was received from all subjects. Testing began in June 1992. Here we report on data collected from the first 340 pairs of twins (all Caucasian). Zygosity was diagnosed by typing eight highly polymorphic DNA microsatellite markers and three blood groups (ABO, MNS, and Rh) in the twins and (in most cases) both parents; in nine instances where DNA was not available, zygosity was judged by similarity of appearance. We endeavoured to test all twins close to their twelfth birthday, but a few pairs were a year older or younger. For the purpose of estimating test-retest reliability, a sub-sample of 33 twin pairs was retested, early in the study, between 2 and 11 weeks (median 4 weeks) after their first visit. The sample and clinical protocol have been described in detail elsewhere [Aitken et al., 1994]. 


\section{$42 \quad$ McGregor et al.}

A nurse examined each individual from the 340 twin pairs and selected the five "most interesting" pigmented skin lesions on their bodies (in general, the most atypical, i.e., the largest, darkest, or those whose boundaries were most irregular). Each selected lesion was numbered with an adhesive label and included in a large-scale video image of the subject's body for accurate identification at the follow-up visit at age 14 (and also for the reliability sub-study), when the same five lesions were re-imaged.

\section{Image Acquisition}

Each selected lesion was imaged twice from a fixed distance $(38 \mathrm{~mm})$ using a custom probe comprising a color CCD (charge-coupled device) video camera (Panasonic WV-CD1E), and a quartz-halogen ring-illuminator (Schott Glaswerke KL1500, Wiesbaden, Germany) operating at a color temperature of 3,000 K. The video signal from the camera was stored temporarily on SVHS videotape (using a Panasonic AG7330 video cassette recorder), before single image frames were digitized and processed using an IBM-compatible Pentium 90 PC and Vision Plus AT color frame grabber. Two 24-bit RGB (Red, Green, and Blue) color digital images of each lesion (one from each of the two video sequences) were acquired, with each image having a resolution of $512(\mathrm{H}) \times 348(\mathrm{~V})$ pixels corresponding to a $32 \times 22 \mathrm{~mm}$ region of the skin. The color and brightness of each image were calibrated with the aid of eight Kodak grey-level color standards, which were mounted permanently within the camera's field of view. The mean RGB values of each standard in each image were compared with corresponding mean values computed across a fixed sample of 10 images, and these ratios were used to define a three-dimensional (3D) piecewise-linear mapping function, which was used to scale the values of all pixels. In total, 6,800 images were obtained from the 340 twin pairs, comprising 2 views of each of the 5 lesions imaged on each individual.

\section{Image Processing}

Custom imaging software written in $\mathrm{C}$ was used to extract features from each image. An automatic boundary-detection algorithm first segmented each image into separate skin- and lesion-regions, and then 15 spatial and color features were computed.

Automatic boundary detection. The lesion boundary was determined automatically using a color thresholding algorithm. A 3D RGB color-space histogram was obtained from each image, in which two major peaks were identified: one peak was assumed to be centred upon the mean skin color, and the other upon the mean lesion color. The 3D color of each pixel in the image was then mapped onto the one-dimensional (1D) vector spanning the mean skin and mean lesion colors, and a 1D histogram computed. The minimum point in the "valley" between the mean-skin and mean-lesion peaks on the 1D histogram was determined, and used as the threshold value to separate lesion pixels from skin pixels. The boundary between these two regions was traced out using a $3 \times 3$ pixel contour-following algorithm [Russ, 1995].

Since correct identification of the lesion boundary was crucial for all subsequent imaging operations, each lesion-image and corresponding boundary was checked visually by a human operator, and images with incorrectly defined boundaries were rejected from the study. Of the 6,800 lesion images, correct boundaries were obtained for 5,850 images (86\%) from 322 twin pairs. 


\section{Color}

Color measurements included the mean $\bar{R}, \bar{G}, \bar{B}$, and variance $V_{R}, V_{G}, V_{B}$, of the RGB pixel values (0-255 grey-levels each) within the lesion boundary, and the mean brightness $\bar{Y}=0.3 \bar{R}+0.59 \bar{G},+0.11 \bar{B}$ [Gonzalez and Woods, 1993].

Size

The size of the lesion was represented by the area $A$ in pixels, and the perimeter $P$, computed by tracking around the boundary and summing up the Euclidean distance (in pixels) for each step.

\section{Symmetry}

Stoecker et al. [1992] suggested a method for measuring the symmetry of a lesion in an image, based upon measuring differences in the lesion's shape when reflected about its "principal axes." Two differences in area $\Delta A_{x}$ and $\Delta A_{y}$, which were when taken as a ratio of the total lesion area were used as the measures of symmetry

$$
\operatorname{Sym} 1=\frac{\Delta A_{x}}{A} \quad \operatorname{Sym} 2=\frac{\Delta A_{y}}{A}
$$

\section{Elongation}

The extent to which a lesion is stretched out, or elongated, can be measured by fitting its shape to an "equivalent ellipse" and computing the ellipse's aspect ratio [Hall et al., 1995]. The equivalent ellipse has equivalent radii of gyration $K_{x}, K_{y}$ [Medalia, 1970] and elongation of the ellipse, and therefore of the lesion, is given by

$$
\text { Elong }=\frac{K_{y}}{K_{x}}
$$

\section{Boundary irregularity}

Two measures of lesion boundary irregularity were used. The first was the "irregularity index" [Golston et al., 1992; Green et al., 1994]

$$
\text { Irreg }=\frac{P^{2}}{4 \pi A}
$$

which measures how different the shape is to a circle. The second measure was the "bulkiness index" [Medalia, 1970; Claridge et al., 1992] defined as

$$
\text { Bulk }=\frac{\text { area of equivalent ellipse }}{\text { area of lesion }}
$$

This index provides a measure of how well multiple copies of the same shape would pack together into a given area. 


\section{$44 \quad$ McGregor et al.}

\section{Edge distinctness}

Some lesions have a distinct change in the pigmentation at their boundary, while others fade gradually into color of the surrounding skin. In order to measure this property, an "edge distinctness index" was derived. A new lesion boundary was computed within the primary boundary based upon a boundary threshold that was $10 \%$ less than the primary threshold value (see Automatic boundary detection above). For lesions with distinct boundaries, the area $A_{s}$ of this new subregion will be similar to the lesion area $A$, but for lesions with fading edges, $A_{s}$ will be much smaller than $A$. The edge distinctness index was defined as [Green et al., 1994]

$$
E d g e=\frac{A-A_{S}}{A}
$$

Further details on computation of indices may be obtained from the authors.

\section{Statistical Analysis}

Of the 322 twin pairs for whom correct lesion boundaries were obtained, we managed to obtain duplicate images of each of five lesions for 366 individuals. However, due to a paucity of suitable lesions in a few subjects, or to contrast or logistic problems, we obtained fewer than the full set of ten images for the remaining 278 subjects. For most variables, measurements were transformed using the square root transformation to stabilise variances and improve normality. Exceptions were Irreg for which an arctan transformation was used, and $\bar{R}, \bar{G}, \bar{B}$, which were not transformed. Transformations were chosen partly on theoretical grounds (e.g., it is logical to apply a square root transformation to variances) and partly on empirical grounds of minimising non-normality. After transformation, for each variable the mean of all ten measurements (or fewer, if there were missing images) was calculated for each subject and it is this mean that is the subject of further genetic analysis. For each subject, we also calculated the mean of duplicates for each of the five lesions and selected the minimum and maximum lesion mean for genetic analysis. However, not surprisingly, it appeared that analysis of the grand mean of all ten images gave the most meaningful results and this is what is reported here.

We used maximum likelihood (ML) analysis of the individual observations in which one can simultaneously test hypotheses about the means, variances, and covariances [Lange et al., 1976; Neale, 1997]. Significant twin correlations establish that there is familial aggregation for the measure of interest. Our task is to distinguish between the possible mechanisms by which this familial likeness may arise. The accepted method is via structural equation modelling as implemented in LISREL, Mx, or similar packages [Neale and Cardon, 1992]. One can conceive of four broad causes of variation, three of which (additive genetic influences "A," genetic dominance "D," and common environment " $C$ ") make family members more alike than random pairs of individuals, and one of which (unique environmental experiences, including error, "E") makes MZ twins and siblings different. The task then is to decide which combination of these four parameters provides the most parsimonious explanation for the observed pattern of $\mathrm{MZ}$ and $\mathrm{DZ}$ twin correlations. The task of choosing an appropriate model is simplified by the fact that $\mathrm{D}$ and $\mathrm{C}$ are entirely negatively confounded so only one of them can appear in a given model. Further, since it is inconceivable that a variable could be measured 
without error, it makes no sense to fit a model without $\mathrm{E}$. In assessing the fit of different submodels, we use the likelihood ratio $\mathrm{c}^{2}$ to balance the joint criteria of fit and parsimony [Neale and Cardon, 1992].

\section{RESULTS}

Complete data were available for 322 pairs comprising 69 monozygotic (MZ) female pairs, $68 \mathrm{MZ}$ male pairs, 50 dizygotic (DZ) female pairs, $56 \mathrm{DZ}$ male pairs, and $79 \mathrm{DZ}$ opposite sex pairs (treated as two groups comprising 35 pairs with the female born first and 44 with the male born first).

Correlations between all 15 variables measured in all 644 individual twins are shown in Table I. Not surprisingly, in view of the measurement algorithms used, many of the variables are highly intercorrelated, and this must be borne in mind when considering the results below.

Each of the six twin groups thus has two means (one each for twin 1 and twin 2), two variances, and one covariance, for a total of 12 means, 12 variances, and 6 covariances, or 30 parameters in all. Initially, a saturated model is fitted estimating all 30 parameters (H0), followed by submodels incorporating successive simplifications. The fit of each submodel is tested by likelihood ratio chi-square test against the preceding, more complex model within which it is nested.

\section{Hypotheses About Means}

The first step is to equate means for twin 1 and twin 2 within same sex twin groups $(\mathrm{H} 1 \mathrm{~m})$. Since twin 1 is always the first born, this tests for any birth order effects. The second step is to equate means of MZ and DZ groups of the same sex $(\mathrm{H} 2 \mathrm{~m})$. The third step is to equate means of female-female pairs with females in opposite-sex pairs, and likewise for males $(\mathrm{H} 3 \mathrm{~m})$. The model now only contains a mean for males and a mean for females and the final step is to equate them so that there is only one mean $(\mathrm{H} 4 \mathrm{~m})$. These contrasts are shown in Table IIa.

For the first three hypotheses, only 1/45 of the likelihood ratio chi-square tests is significant at the $5 \%$ level, which we can attribute to chance (Table III). However, for $\mathrm{H} 4 \mathrm{~m}$ we find significant differences in the means of males and females for 5/15 variables, including all the color means. This suggests that females have lesions that are significantly lighter in color than those of males, in accord with the generally lighter pigmentation of females [Kalla and Tiwari, 1970]. For simplicity, we therefore retain separate means for males and females for all variables.

\section{Hypotheses About Variances}

The same set of contrasts (Table IIa) is used to test hypotheses about variances (Table III). These are performed against a baseline of $\mathrm{H} 3 \mathrm{~m}$, i.e., with separate means for males and females otherwise constrained equal across all six twin groups. Considering all four hypotheses $\mathrm{H} 1 \mathrm{v}-\mathrm{H} 4 \mathrm{v}$, for the first nine variables we find only $1 / 36$ contrasts significant at the 5\% level. However, for the last six variables, which are all compound indices of shape, we find 16/24 contrasts significant suggesting that these variables may have poor measurement properties. Since the sex contrast seems no more significant than any other, for simplicity we proceed with only a single parameter to estimate variance. 
TABLE I. Correlations Between Variables Measuring Color and Shape of Melanocytic Naevi in 644 Twin Individuals

\begin{tabular}{|c|c|c|c|c|c|c|c|c|c|c|c|c|c|c|c|}
\hline & \multicolumn{15}{|c|}{ Correlation } \\
\hline & $\overline{\mathrm{R}}$ & $\overline{\mathrm{G}}$ & $\overline{\mathrm{B}}$ & $\overline{\mathrm{Y}}$ & $\mathrm{V}_{\mathrm{R}}$ & $\mathrm{V}_{\mathrm{G}}$ & $\mathrm{V}_{\mathrm{B}}$ & Area & $\mathrm{P}$ & Irreg & Elong & Bulk & Sym1 & Sym2 & Edge \\
\hline Red mean & 1.00 & & & & & & & & & & & & & & \\
\hline Green mean & .90 & 1.00 & & & & & & & & & & & & & \\
\hline Blue mean & .66 & .89 & 1.00 & & & & & & & & & & & & \\
\hline Brightness & .95 & .99 & .84 & 1.00 & & & & & & & & & & & \\
\hline Variance of red & .59 & .67 & .55 & .66 & 1.00 & & & & & & & & & & \\
\hline Variance of green & .33 & .47 & .45 & .43 & .90 & 1.00 & & & & & & & & & \\
\hline Variance of blue & .01 & .13 & .13 & .08 & .71 & .86 & 1.00 & & & & & & & & \\
\hline Size of the lesion & .12 & .18 & .15 & .16 & .24 & .29 & .21 & 1.00 & & & & & & & \\
\hline Perimeter & .00 & .09 & .08 & .06 & .08 & .13 & .08 & .95 & 1.00 & & & & & & \\
\hline Irregularity index & .32 & .23 & .16 & .27 & .35 & .33 & .27 & .29 & .56 & 1.00 & & & & & \\
\hline Elongation index & .08 & .03 & .00 & .05 & .01 & .05 & .09 & .15 & .20 & .23 & 1.00 & & & & \\
\hline Bulkiness index & .29 & .26 & .18 & .28 & .43 & .47 & .40 & .33 & .04 & .73 & .07 & 1.00 & & & \\
\hline Primary symmetry index & .31 & .29 & .20 & .30 & .44 & .49 & .40 & .34 & .06 & .71 & .03 & .96 & 1.00 & & \\
\hline Secondary symmetry index & .27 & .24 & .16 & .26 & .40 & .45 & .37 & .33 & .06 & .68 & .08 & .98 & .95 & 1.00 & \\
\hline Edge distinctness index & .68 & .78 & .70 & .77 & .78 & .73 & .47 & .42 & .20 & .47 & .04 & .65 & .66 & .60 & 1.00 \\
\hline
\end{tabular}


TABLE II. Contrasts Used to Test Hypotheses About Means $\left(H_{M}\right)$, Variances $\left(H_{V}\right)$, and Covariances $\left(\mathrm{H}_{\mathrm{C}}\right)$ of Naevus Characteristics in Twins

\begin{tabular}{|c|c|c|c|c|c|c|c|c|c|c|}
\hline & \multicolumn{2}{|c|}{$\mathrm{H} 0_{\mathrm{M}, \mathrm{V}}$} & \multicolumn{2}{|c|}{$\mathrm{H} 1_{\mathrm{M}, \mathrm{V}}$} & \multicolumn{2}{|c|}{$\mathrm{H} 2_{\mathrm{M}, \mathrm{V}}$} & \multicolumn{2}{|c|}{$\mathrm{H} 3_{\mathrm{M}, \mathrm{V}}$} & \multicolumn{2}{|c|}{$\mathrm{H} 4_{\mathrm{M}, \mathrm{V}}$} \\
\hline & tw1 & tw2 & tw1 & tw2 & tw1 & tw2 & tw1 & tw2 & tw1 & tw2 \\
\hline \multicolumn{11}{|c|}{ a. Means and Variances } \\
\hline MZFF & 1 & 2 & 1 & 1 & 1 & 1 & 1 & 1 & 1 & 1 \\
\hline MZMM & 3 & 4 & 2 & 2 & 2 & 2 & 2 & 2 & 1 & 1 \\
\hline DZFF & 5 & 6 & 3 & 3 & 1 & 1 & 1 & 1 & 1 & 1 \\
\hline DZMM & 7 & 8 & 4 & 4 & 2 & 2 & 2 & 2 & 1 & 1 \\
\hline DZFM & 9 & 10 & 5 & 6 & 3 & 4 & 1 & 2 & 1 & 1 \\
\hline \multirow[t]{2}{*}{ DZMF } & 11 & 12 & 7 & 8 & 5 & 6 & 2 & 1 & 1 & 1 \\
\hline & \multicolumn{2}{|c|}{$\mathrm{H}_{\mathrm{C}}$} & \multicolumn{2}{|c|}{$\mathrm{H} 1_{\mathrm{C}}$} & \multicolumn{2}{|c|}{$\mathrm{H} 2_{\mathrm{C}}$} & \multicolumn{2}{|c|}{$\mathrm{H} 3_{\mathrm{C}}$} & \multicolumn{2}{|c|}{$\mathrm{H} 4_{\mathrm{C}}$} \\
\hline \multicolumn{11}{|c|}{ b. Covariances (from baseline of $\mathrm{H} 3_{\mathrm{M}}+\mathrm{H} 4_{\mathrm{V}}$ ) } \\
\hline MZFF & \multicolumn{2}{|c|}{1} & \multicolumn{2}{|c|}{1} & \multicolumn{2}{|c|}{1} & \multicolumn{2}{|c|}{1} & \multicolumn{2}{|c|}{0} \\
\hline MZMM & \multicolumn{2}{|c|}{2} & \multicolumn{2}{|c|}{1} & \multicolumn{2}{|c|}{1} & \multicolumn{2}{|c|}{1} & \multicolumn{2}{|c|}{0} \\
\hline DZFF & \multicolumn{2}{|c|}{3} & \multicolumn{2}{|c|}{2} & \multicolumn{2}{|c|}{2} & \multicolumn{2}{|c|}{1} & \multicolumn{2}{|c|}{0} \\
\hline DZMM & \multicolumn{2}{|c|}{4} & \multicolumn{2}{|c|}{2} & \multicolumn{2}{|c|}{2} & \multicolumn{2}{|c|}{1} & \multicolumn{2}{|c|}{0} \\
\hline DZFM & \multicolumn{2}{|c|}{5} & \multicolumn{2}{|c|}{3} & & & & & ( & \\
\hline DZMF & & 5 & & & & & & & ( & \\
\hline
\end{tabular}

\section{Hypotheses About Covariances}

While the foregoing tests of hypotheses concerning means and variances are important to establish regularities of sampling and measurement, the central interest of twin studies is, of course, the contrast of covariances. If a trait is genetically influenced, one expects the MZ covariance to be greater than its DZ counterpart. However, one does not necessarily expect the size or nature of genetic influence to be the same in males and females and it is, therefore, important to test preliminary hypotheses concerning sex, as well as zygosity differences in covariances. These contrasts are shown in Table IIb and the tests are all performed against a baseline of $\mathrm{H} 4 \mathrm{v}$, i.e., separate means for males and females but only one common variance estimate.

$\mathrm{H} 1 \mathrm{c}$ allows all six covariances to be different but $\mathrm{H} 2 \mathrm{c}$ constrains the covariances of MZ female and MZ male pairs equal, as well as those of the DZ females and DZ males; the two opposite-sex covariances are also constrained equally. H2c, therefore, rules out the possibility of scalar sex limitation in which genetic or environmental influences may have different magnitudes in males and females. It does not, however, rule out the possibility that there are genes of different kinds acting in males and females, which would result in the opposite sex covariance being lower than the DZ same sex covariances. This latter hypothesis of non-scalar sex limitation is explicitly ruled out in $\mathrm{H} 3 \mathrm{c}$, which constrains all four DZ covariances equal, and represents the genetic hypothesis at its simplest. The genetic hypothesis may be formally tested by comparing the fit of $\mathrm{H} 3 \mathrm{c}$ with $\mathrm{H} 4 \mathrm{c}$ in which all five covariances are constrained equal (tantamount to saying that all familial aggregation is due to shared family environment). Finally, we should formally test whether there is any familial aggregation to explain at all, and this is done in $\mathrm{H} 5 \mathrm{c}$ where all covariances are constrained to zero (equivalent to the hypothesis that the only source of individual differences is environmental factors unique to the individual, including developmental accidents and measurement error). 
TABLE III. Likelihood Ratio Chi-Square Values $\left(\Delta \chi^{2}\right)$ for Tests Concerning Means (M), Variances (V), and Covariances (C) of Naevus Characteristics in 322 Pairs of 12-Year-Old Twins

\begin{tabular}{|c|c|c|c|c|c|c|c|c|c|c|c|c|c|c|c|c|}
\hline \multirow[b]{2}{*}{ Hypothesses } & \multirow[b]{2}{*}{ d.f. } & \multicolumn{15}{|c|}{$\Delta \chi^{2}$ values for mole image measurements } \\
\hline & & $\overline{\mathrm{R}}$ & $\overline{\mathrm{G}}$ & $\overline{\mathrm{B}}$ & $\overline{\mathrm{Y}}$ & $\mathrm{V}_{\mathrm{R}}$ & $\mathrm{V}_{\mathrm{G}}$ & $\mathrm{V}_{\mathrm{B}}$ & Area & $\mathrm{P}$ & Irreg & Elong & Bulk & Sym 1 & Sym2 & Edge \\
\hline $\mathrm{H} 1_{\mathrm{M}}$ & 4 & 4.74 & 5.63 & 2.54 & 5.02 & 7.06 & 7.42 & 4.63 & 2.15 & 3.15 & 5.34 & 4.00 & 8.46 & 6.39 & 7.76 & 7.42 \\
\hline $\mathrm{H} 2_{\mathrm{M}}$ & 2 & $6.89^{\mathrm{a}}$ & 1.59 & 1.95 & 2.94 & 0.89 & 0.95 & 1.33 & 0.89 & 1.09 & 0.19 & 0.54 & 0.99 & 0.46 & 1.72 & 0.09 \\
\hline $\mathrm{H} 3_{\mathrm{M}}$ & 4 & 6.97 & 3.36 & 3.21 & 4.07 & 2.18 & 1.01 & 5.88 & 4.39 & 4.66 & 3.87 & 5.29 & 4.03 & 3.24 & 4.42 & 1.24 \\
\hline $\mathrm{H} 4_{\mathrm{M}}$ & 1 & $11.6^{\mathrm{c}}$ & $12.1^{\mathrm{c}}$ & $11.5^{\mathrm{c}}$ & $12.9^{\mathrm{c}}$ & 0.04 & 1.70 & $6.43^{\mathrm{c}}$ & 3.27 & 3.75 & 0.08 & 0.29 & 0.84 & 0.95 & 1.07 & 3.35 \\
\hline $\mathrm{H} 1_{\mathrm{V}}$ & 4 & 5.70 & 5.49 & 5.87 & 5.98 & 6.17 & 4.26 & 3.86 & 0.46 & 1.18 & $10.7^{\mathrm{a}}$ & 6.22 & $9.90^{\mathrm{a}}$ & $13.3^{\mathrm{c}}$ & $9.60^{\mathrm{a}}$ & $11.0^{\mathrm{a}}$ \\
\hline $\mathrm{H} 2 \mathrm{v}$ & 2 & 1.21 & 0.21 & 1.69 & 0.36 & 1.82 & 3.32 & 1.51 & 1.23 & 0.71 & 1.66 & 0.43 & $10.6^{\mathrm{a}}$ & $10.2^{\mathrm{c}}$ & $11.6^{\mathrm{c}}$ & 1.55 \\
\hline $\mathrm{H} 3_{\mathrm{V}}$ & 4 & 1.75 & 6.78 & 5.95 & 4.95 & 7.97 & 2.48 & 3.94 & 0.83 & 0.31 & $9.50^{\mathrm{a}}$ & 5.94 & $21.8^{\mathrm{c}}$ & $12.6^{\mathrm{b}}$ & $23.7^{\mathrm{c}}$ & 3.89 \\
\hline $\mathrm{H} 4_{\mathrm{V}}$ & 1 & $3.98^{\mathrm{a}}$ & 1.60 & 0.01 & 2.45 & 0.26 & 0.56 & 0.13 & 0.18 & 1.56 & $6.77^{\mathrm{b}}$ & 0.18 & $6.26^{\mathrm{a}}$ & $4.60^{\mathrm{a}}$ & $6.94^{\mathrm{a}}$ & 1.27 \\
\hline $\mathrm{H} 1_{\mathrm{C}}$ & 3 & 1.88 & 5.34 & 4.88 & 3.87 & 0.55 & 2.25 & $8.25^{\mathrm{a}}$ & 2.95 & 4.30 & 2.03 & 0.77 & 1.07 & 1.83 & 1.78 & 1.81 \\
\hline $\mathrm{H} 2_{\mathrm{C}}$ & 1 & 1.37 & 1.15 & 0.02 & 1.00 & $4.78^{\mathrm{a}}$ & 1.63 & 1.52 & 0.78 & 0.23 & 0.09 & 1.86 & 0.55 & 0.09 & 0.21 & 1.43 \\
\hline $\mathrm{H} 3_{\mathrm{C}}$ & 1 & $28.3^{\mathrm{c}}$ & $33.0^{\mathrm{c}}$ & $33.7^{\mathrm{c}}$ & $31.7^{\mathrm{c}}$ & $18.7^{\mathrm{c}}$ & $12.2^{\mathrm{c}}$ & $11.6^{\mathrm{c}}$ & $13.0^{\mathrm{c}}$ & $11.3^{\mathrm{c}}$ & $4.43^{\mathrm{a}}$ & 1.57 & 3.78 & $7.11^{\mathrm{b}}$ & 1.98 & $13.1^{\mathrm{c}}$ \\
\hline $\mathrm{H} 4_{\mathrm{C}}$ & 1 & $241^{\mathrm{c}}$ & $136^{\mathrm{c}}$ & $185^{\mathrm{c}}$ & $161^{\mathrm{c}}$ & $89.2^{\mathrm{c}}$ & $75.0^{\mathrm{c}}$ & $123^{\mathrm{c}}$ & $93.7^{\mathrm{c}}$ & $69.3^{\mathrm{c}}$ & $37.2^{c}$ & 3.81 & $41.6^{\mathrm{c}}$ & $44.5^{\mathrm{c}}$ & $33.5^{\mathrm{c}}$ & $89.6^{\mathrm{c}}$ \\
\hline
\end{tabular}

${ }^{\mathrm{a}} 0.01<P<0.05$.

${ }^{\mathrm{b}} 0.001<P<0.01$.

${ }^{\mathrm{c}} P<0.001$. 
Tests of these hypotheses are shown at the foot of Table III. For H2c, tested against $\mathrm{H} 1 \mathrm{c}$, we find $1 / 15$ tests significant (for $\mathrm{V}_{\mathbf{B}}$ ), and for $\mathrm{H} 3 \mathrm{c}$, tested against $\mathrm{H} 2 \mathrm{c}$, we also find $1 / 15$ significant results (for $V_{R}$ ). While these results may imply some form of sex limited gene expression for these variables, we proceed on the assumption that they are due to chance. The focus of interest is on the test of $\mathrm{H} 4 \mathrm{c}$ (against $\mathrm{H} 3 \mathrm{c}$ ) for the presence of genetic variance and this is significant at the 5\% level for $12 / 15$ variables and at the $0.1 \%$ level for $10 / 15$ variables. Not surprisingly then, the hypothesis that there is no familial aggregation $(\mathrm{H} 5 \mathrm{c})$ is firmly rejected for all variables but one (Elong), suggesting that variation in this shape index is either completely determined by chance influences unique to the individual, or is plagued by measurement error.

Twin correlations estimated for all six groups (H1c) are shown in Table IV, as well as the pooled correlations for MZ pairs and DZ pairs estimated from $\mathrm{H} 3 \mathrm{c}$. The 95\% confidence intervals are also given for the latter.

\section{Structural Equation Modelling of Genetic Hypotheses}

While the above sequence of models tests for the presence of genetic effects, it does not directly estimate the size of genetic influence on each variable. The full ACE model is fitted to the raw data against the baseline of model H3m (Table III), which specifies only a male and female mean, but otherwise makes no restrictions on the size of variances and covariances of twins. Our new model, therefore, attempts to summarise all 12 twin variances and 6 covariances (18 statistics in all) in terms of, at most, three parameters (A,C, and E), hence generating a likelihood ratio chi-square test for 15 degrees of freedom. We also fit submodels to test whether we can drop $\mathrm{A}$ or $\mathrm{C}$ from the model (or both). It makes no sense to drop $\mathrm{E}$ from the model since that is tantamount to saying that there is no measurement error and that MZ twins must be perfectly correlated.

Standardised variance estimates for the preferred model (either ACE, AE, or $\mathrm{CE}$ ) are shown in Table $\mathrm{V}$ along with the corresponding likelihood ratio chi-square for 15 degrees of freedom (ACE model), or 16 degrees of freedom (AE or CE models), and the corresponding probability level. For the first nine variables, either the ACE or AE model fits the data well, with estimates of genetic variance accounting for between 40 and $79 \%$ of the total. For the last six variables, however, the results are more suspect, with very bad fits of the model to four variables (Irreg, Bulk, Sym1, and Sym2) and no apparent familial aggregation at all for Elong. While the fit of the model to Edge is adequate, and the heritability is significant, this result must remain suspect because of the large inequality of twin 1 and twin 2 variances revealed by H4v (Table III).

\section{DISCUSSION}

Our results show conclusively that there are major genetic influences on color and size of lesions accounting for between $40-80 \%$ of total variance. Demonstration of genetic influences on various indices of shape is more problematic, with directional evidence that there are such factors (i.e., the MZ correlation is greater than the DZ correlation), but considerable difficulties with the measurement properties of these indices. 
TABLE IV. Twin Correlations for Six Sex/Zygosity Groups (From H0 ), and for Total MZ and Total DZ Pairs (From H2 ${ }_{\mathrm{C}}$ With $95 \%$ Confidence Intervals

\begin{tabular}{|c|c|c|c|c|c|c|c|c|c|c|c|c|c|c|c|c|}
\hline ZYG & Pairs & $\overline{\mathrm{R}}$ & $\overline{\mathrm{G}}$ & $\overline{\mathrm{B}}$ & $\bar{Y}$ & $V_{R}$ & $\mathrm{~V}_{\mathrm{G}}$ & $\mathrm{V}_{\mathrm{B}}$ & Area & $\mathrm{P}$ & Irreg & Elong & Bulk & Sym1 & Sym2 & Edge \\
\hline MZFF & 69 & .83 & .80 & .79 & .78 & .69 & .51 & .68 & .65 & .61 & .35 & .02 & .40 & .43 & .27 & .61 \\
\hline DZFF & 50 & .68 & .56 & .57 & .58 & .43 & .35 & .41 & .55 & .53 & .36 & .26 & .38 & .30 & .31 & .43 \\
\hline MZMM & 68 & .86 & .81 & .86 & .83 & .68 & .67 & .71 & .66 & .59 & .51 & .06 & .52 & .59 & .49 & .70 \\
\hline DZMM & 56 & .68 & .48 & .54 & .54 & .52 & .52 & .61 & .33 & .23 & .23 & .23 & .29 & .30 & .28 & .47 \\
\hline DZFM & 35 & .53 & .20 & .45 & .31 & .22 & .40 & .61 & .26 & .29 & .30 & .16 & .29 & .18 & .31 & .22 \\
\hline DZMF & 44 & .64 & .53 & .64 & .56 & .25 & .14 & .18 & .40 & .30 & .21 & .01 & .23 & .30 & .23 & .38 \\
\hline $\begin{array}{l}\text { MZ } \\
95 \% \text { CI }\end{array}$ & 137 & .84 & .77 & .81 & .79 & .65 & .59 & .68 & .65 & .59 & .42 & .01 & .40 & .45 & .34 & .62 \\
\hline Upper & & .88 & .83 & .86 & .84 & .74 & .69 & .76 & .73 & .69 & .55 & .18 & .54 & .57 & .48 & .72 \\
\hline Lower & & .78 & .69 & .75 & .71 & .54 & .47 & .58 & .54 & .47 & .28 & -.15 & .26 & .30 & .18 & .51 \\
\hline $\begin{array}{l}\text { DZ } \\
95 \% \text { CI }\end{array}$ & 185 & .66 & .48 & .57 & .53 & .40 & .37 & .49 & .40 & .34 & .27 & .17 & .29 & .31 & .30 & .41 \\
\hline Upper & & .74 & .58 & .66 & .63 & .51 & .49 & .59 & .52 & .46 & .40 & .31 & .44 & .44 & .43 & .52 \\
\hline Lower & & .57 & .36 & .46 & .42 & .27 & .24 & .37 & .28 & .21 & .13 & .03 & .19 & .18 & .17 & .29 \\
\hline
\end{tabular}


TABLE V. Results of Fitting Genetic and Environmental Models to Raw Data Judged Against a Model Assuming Only Separate Male and Female Means $\left(\mathrm{H3}_{\mathrm{M}}\right)^{*}$

\begin{tabular}{lcccccccccccccccc}
\hline Parameters & $\overline{\mathrm{R}}$ & $\overline{\mathrm{G}}$ & $\overline{\mathrm{B}}$ & $\overline{\mathrm{Y}}$ & $\mathrm{V}_{\mathrm{R}}$ & $\mathrm{V}_{\mathrm{G}}$ & $\mathrm{V}_{\mathrm{B}}$ & Area & $\mathrm{P}$ & Irreg & Elong & Bulk & Sym1 & Sym2 & Edge \\
\hline $\mathrm{A}$ & .40 & .79 & .55 & .58 & .70 & .64 & .43 & .67 & .61 & .47 & - & .50 & .54 & .45 & .67 \\
$\mathrm{C}$ & .45 & - & .28 & .22 & - & - & .27 & - & - & - & .11 & - & - & - & - & - \\
$\mathrm{E}$ & .15 & .21 & .17 & .20 & .30 & .36 & .30 & .33 & .39 & .53 & .89 & .50 & .46 & .55 & .33 \\
$\chi^{2}{ }_{16}$ & $14.9^{\mathrm{a}}$ & 21.9 & $18.6^{\mathrm{a}}$ & $18.0^{\mathrm{a}}$ & 22.2 & 17.4 & $19.9^{\mathrm{a}}$ & 6.9 & 8.5 & 30.8 & 16.8 & 51 & 42.5 & 54 & 21.9 \\
$p$ & .46 & .15 & .23 & .26 & .14 & .36 & .18 & .98 & .93 & .014 & .40 & .000 & .000 & .000 & .146 \\
\hline
\end{tabular}

*Standardized variances components are shown for the preferred model which may contain additive genetic (A), common environment (C) or unique environment (E) effects.

${ }^{\mathrm{a}} \chi^{2}$ on 15 degrees of freedom. 


\section{$52 \quad$ McGregor et al.}

Having shown that genetic influences on lesion features exist, the challenge of the future is to identify the genes causing these features. For the size variables, obvious candidates are the same (as yet unknown) genes that influence the number of naevi, possibly involving tumor suppressor genes such as CDKN2 or others affecting the progression of melanocytes to naevi to melanoma. For color features, genes influencing pigmentation in skin, hair, eyes, or elsewhere may be important. Dissecting these gene effects and understanding how they jointly produce skin lesions of such phenotypic variety, and with such differences in their liability to progress to malignancy, could prove to be a most worthwhile approach to the vexed question of the etiology of melanoma.

For certain variables, notably those measuring color, we also estimate significant components of shared environmental influence accounting for $22-45 \%$ of variance. While sun exposure, shared by co-twins in the course of family life (and as 12-year-olds, most of their leisure and non-leisure activities will be together) is the most obvious explanation for this, we cannot rule out that observer bias in the selection of naevi for imaging may also play a part.

The latter is undoubtedly the weakest feature of our study. An alternative method would have been a strict, randomised protocol for the selection of naevi, but this would usually have been difficult and time consuming to apply and would frequently have resulted in the omission of the "most interesting" lesions on the skin. While the selection of naevi was somewhat arbitrary, it did not prevent detection of large replicable differences between individuals in their naevus characteristics. In our earlier reliability study of 66 of the twins measured twice at a 1-month interval, we estimated that $62-76 \%$ of variance in the mean of five lesions per subject occurred between individuals for all variables but one. The exception was a "fragmentation index" (the inverse of Irreg in the present study) where only 43\% was accounted for. These reliability measures are remarkably close to the sum of additive and shared environmental variance $(\mathrm{A}+\mathrm{C})$ estimated from the full twin study (Table $\mathrm{V})$, suggesting that the estimate of unique environmental variance (E) largely reflects measurement errors and, more particularly, inconsistencies between the characteristics of individual lesions within a subject. For most variables, therefore, one can say that in so far as one can measure lesion characteristics reliably and consistently between individuals, differences between individuals in the mean levels of characteristics are largely genetic in origin. The exceptions are the few color variables mentioned, which have modest but significant shared environmental influences as well.

\section{ACKNOWLEDGMENTS}

This work was supported by grants from the Queensland Cancer Fund and the National Health and Medical Research Council (901061 and 950998). We thank the twins and their parents for their cooperation.

\section{REFERENCES}

Aitken JF, Green A, Eldridge A, Green L, Pfitzner J, Battistutta D, Martin NG (1994): Comparability of naevus counts between and within examiners, and comparison with computer image analysis. Br J Cancer 69:487-91. 
Aitken JF, Pfitzner J, Battistutta D, O’Rourke PK, Green AC, Martin NG (1996): Reliability of computer image analysis of pigmented skin lesions of Australian adolescents. Cancer 78:252-257.

Briollais L, Chompret A, Guilloud-Bataille M, Feingold N, Avril M, Demenais F (1996): Genetic and epidemiological risk factors for a malignant melanoma-predisposing phenotype: The great number of nevi. Genet Epidemiol 13:385-402.

Claridge E, Hall PN, Keefe M, Allen, JP (1992): Shape analysis for classification of malignant melanoma. J Biomed Eng 14:229-234.

Duffy DL, Macdonald AM, Easton DF, Ponder BAJ, Martin NG (1992): Is the genetics of moliness simply the genetics of sun exposure? A path analysis of nevus counts and risk factors in British twins. Cytogenet Cell Genet 59:194-196.

Goldgar DE, Cannon-Albright LA, Meyer LJ, Piepkorn MW, Zone JJ, Skolnick MH (1991): Inheritance of nevus number and size in melanoma and dysplastic nevus syndrome kindreds. $J$ Natl Cancer Inst 83:1726-1733.

Golston JE, Stoecker WV, Moss RH, Dhillon IPS (1992): Automatic detection of irregular borders in melanoma and other skin tumors. Comput Med Imag Graphics 16:199-203.

Gonzalez RC, Woods RE (1993): "Digital Image Processing." Reading, MA: Addison-Wesley.

Green A, Swerdlow AJ (1989): Epidemiology of melanocytic naevi. Epidemiol Rev 11:204-221.

Green A, Martin N, McKenzie G, Pfitzner J, Quintarelli F, Thomas BW, O'Rourke M, Knight N (1991): Computer image analysis of pigmented skin lesions. Melanoma Res 1:231-236.

Green A, Martin N, Pfitzner J, O'Rourke M, Knight N (1994): Computer image analysis in the diagnosis of melanoma. J Am Acad Dermatol 31:958-964.

Hall PN, Claridge E, Morris Smith JD (1995): Computer screening for early detection of melanoma: Is there a future? Br J Dermatol 132:323-338.

Kalla AK, Tiwari SC (1970): Sex differences in skin colour in man. Acta Genet Med Gemellol 19:472-476.

Kelly JW, Rivers JK, MacLennan R, Harrison S, Lewis AE, Tate BJ (1994): Sunlight: A major factor associated with the development of melanocytic nevi in Australian schoolchildren. J Am Acad Dermatol 30:40-48.

Lange K, Westlake J, Spence MA (1976): Extensions to pedigree analysis. III. Variance components by the scoring method. Ann Hum Genet 39:485-491.

MacLennan R, Green AC, McLeod GRC, Martin NG (1992): Increasing incidence of cutaneous melanoma in Queensland, Australia. J Natl Cancer Inst 84:1427-1432.

Medalia AI (1970): Dynamic shape factors of particles. Powder Technol 4:117-138.

Neale MC (1997): "Mx: Statistical Modelling,” 4th edition. Richmond, VA: Department of Psychiatry, Medical College of Virginia.

Neale MC, Cardon LR (1992): "Methodology for Genetic Studies of Twins and Families." Dordrecht: Kluwer Academic Publishers.

Rosenfeld A, Kak AC (1981): "Digital Picture Processing," 2nd ed. New York: Academic Press.

Russ JC (1995): “The Image Processing Handbook,” 2nd ed. Boca Raton: CRC Press.

Stoecker WV, Li WW, Moss RH (1992): Automatic detection of asymmetry in skin tumors. Comput Med Imag Graphics 16:191-197.

Swerdlow AJ, Green A (1987): Melanocytic naevi and melanoma: An epidemiologic perspective. Br J Dermatol 117:137-146.

Swerdlow AJ, English J, MacKie RM, O’Doherty CJ, Hunter JAA, Clark J, Hole DJ (1986): Benign melanocytic naevi as a risk factor for malignant melanoma. BMJ 292:1555-1559. 